\title{
Study of hysteroscopic evaluation in patients with abnormal uterine bleeding
}

\author{
Ashok Kumar K., Sathya P., Sreelatha Sampathkumar*
}

Department of Obstestrics and Gynecology, ESIC MC PGIMSR Rajainagar, Bangalore, Karnataka, India

Received: 19 January 2017

Accepted: 28 February 2017

\section{*Correspondence:}

Dr. Sreelatha Sampathkumar,

E-mail: drsreelatha2011@gmail.com

Copyright: (c) the author(s), publisher and licensee Medip Academy. This is an open-access article distributed under the terms of the Creative Commons Attribution Non-Commercial License, which permits unrestricted non-commercial use, distribution, and reproduction in any medium, provided the original work is properly cited.

\begin{abstract}
Background: Abnormal uterine bleeding in women is the commonest presenting complaint which accounts for one third of all gynecological consultations. It not only causes discomfort, inconvenience to healthy women but also affects their quality of life and impose financial burden on them. This insists the physician to diagnose its etiology and provide appropriate treatment. Hysteroscopy guided biopsy is a simple, safe, reliable procedure in the diagnosis of abnormal uterine bleeding. The objective of the study was to evaluate the uterine pathology in premenopausal women with abnormal uterine bleeding by hysteroscopy.

Methods: This prospective study was conducted at ESIC-MC and PGIMSR, Rajajinagar, Bangalore, in 50 premenopausal women with abnormal uterine bleeding over 18 months from Dec 2012 to May 2014. All 50 women were subjected to diagnostic hysteroscopy followed by curettage. The sample was sent to histopathological examination. Data was collected and analyzed.

Results: In the present study, abnormal uterine bleeding was more common in 41-45yrs of age. The commonest presenting complaint was heavy menstrual bleeding (menorrhagia) in $54 \%$ of cases. The abnormal findings on hysteroscopy were: Hyperplasia $42 \%$, endometrial polyp $22 \%$, sub-mucous myoma $4 \%$, carcinoma endometrium $2 \%$, synechiae $2 \%$ and endometritis $2 \%$. Negative hysteroscopic view was seen in $26 \%$. The sensitivity, specificity, positive and negative predictive value of hysteroscopy was $91.89 \%, 92.31 \%, 97.14 \%$ and $80 \%$ respectively. The overall diagnostic accuracy of hysteroscopy was $92 \%$.

Conclusions: Hysteroscopy and its directed biopsy renders high diagnostic accuracy in patients with abnormal uterine bleeding and thereby guiding them for further management.
\end{abstract}

Keywords: Abnormal uterine bleeding, Histopathological examination, Hysteroscopy

\section{INTRODUCTION}

Abnormal uterine bleeding is one of the most common problems that challenge the gynaecologist. Virtually every woman will at some point in her lifetime experience episodes of bleeding that will be perceived as abnormal. Abnormal uterine bleeding (AUB) is defined as any type of bleeding in which the duration, frequency, or amount is abnormal for an individual patient. ${ }^{1}$

Abnormal uterine bleeding is responsible for more than one-third of gynaecologic consultations and nearly twothirds of hysterectomies. ${ }^{1}$ It is estimated that a woman has a 1 in 20 lifetime chance of consulting her primary physician because of menorrhagia. ${ }^{2}$ Abnormal uterine bleeding occurs in 9 to $14 \%$ of women between menarche and menopause, significantly affecting quality of life and imposing financial burden. ${ }^{3}$

Abnormal uterine bleeding can be caused by wide variety of disorders. Although it may represent a normal physiological state which warrants only observation, it can also be an indirect sign of other more or less serious underlying disease necessitating aggressive treatment that could even warrant a hysterectomy. Because of its broad range of differential diagnosis, the diagnosis of AUB can 
be quite challenging; despite a detailed history, various blood tests, and a thorough pelvic examination often involving ultrasonography, the cause of the bleeding is established only in $50-60 \%$ of cases. ${ }^{4}$

Before instituting any therapy, the clinician should make a correct diagnosis. Many authors have suggested endometrial sampling must be taken in all women $\geq 35$ years old with abnormal uterine bleeding. Though Dilatation \& Curettage was the primary method of evaluating AUB before the evolution of hysteroscopy, it is a blind and incomplete procedure. It will only scrape less than $50 \%$ of the endometrial cavity in $60 \%$ of the patients. ${ }^{5} \mathrm{D}$ and $\mathrm{C}$ is less accurate than hysteroscopy in diagnosing structural pathology such as polyps, fibroids, intrauterine adhesions and congenital malformations and has a cancer detection failure rate of $0.9 \%{ }^{6}$

TVS has a high false-negative rate and less accurate than hysteroscopy in diagnosing focal intrauterine pathology. ${ }^{7}$ Though the ultimate gold standard in uterine cavity evaluation is hysterectomy, it cannot be used as a diagnostic tool. ${ }^{8}$ Instead of that, Hysteroscopy can be used as a diagnostic tool as it permits direct visualisation of the cervical canal and uterine cavity, enabling observation of intrauterine abnormalities. This safe procedure will lead to more accurate diagnosis and specific surgical or medical treatment directed at the specific pathology and will avoid the need for major surgery.

According to valle, hysteroscopy is not a substitute for tissue diagnosis. ${ }^{9}$ Hysteroscopy combined with histopathologic examination is the new "gold standard" method for evaluating the cases of AUB. ${ }^{10}$

This study has been done to evaluate the causes of abnormal uterine bleeding by hysteroscopy. It also analyzes the accuracy of hysteroscopic diagnosis and its correlation with histopathological findings.

Aims and objectives of the study were to evaluate the intrauterine pathology in premenopausal women with abnormal uterine bleeding.

\section{METHODS}

This prospective study was conducted in the Department of Obstetrics and Gynecology, ESIC-MC and PGIMSR, Rajajinagar, Bangalore.

\section{Inclusion criteria}

Heavy menstrual bleeding (Menorrhagia), Intermenstrual bleeding (Metrorrhagia), Intermenstrual heavy bleeding (Menometrorrhagia), Frequent cycles (Polymenorrhea), Frequent and heavy menstrual bleeding (Polymenorrhagia), Infrequent menstrual bleeding (Oligomenorrhea).

\section{Exclusion criteria}

Fibroid uterus, IUCD (Intrauterine contraceptive devices), Hormone producing Ovarian tumours in USG, Endocrine disorders like hyperthyroidism- or hypothyroidism, adrenal disease, prolactin disorders, Coagulation disorders, liver/renal diseases, Cervical malignancy on medications like steroids, neuroleptics and anticoagulants, Pregnancy.

\section{Materials used}

Rigid Hysteroscope with 300 fore oblique view lens (stryker), light source, uterine distension medium, video camera system and D and $\mathrm{C}$ set.

A thorough history was elicited from those women chosen for study. All the study subjects were analyzed in full details regarding age, literacy, socioeconomic status, parity, menstrual history, etc.

Subjects were followed further by thorough general physical, systemic and gynaecological examinations. All the patients were investigated to rule out organic causes of AUB with CBC, RFT, LFT, Blood grouping and Rh typing, coagulation profile, thyroid function tests and Urine pregnancy test to rule out pregnancy and Ultrasonography in OPD basis. Chest x-ray posteroanterior view and ECG was done for preanesthetic evaluation. After getting physician and anesthetist fitness, patients were called on day 7-10 of their menstrual cycle and admitted to the hospital. After getting informed written consent for the procedure, patient has been kept nil orally for 6 hours before the procedure and diagnostic hysteroscopy was performed, D and C was done and endometrial tissue sent for histopathological examination.

\section{RESULTS}

Table 1: Age incidence.

\begin{tabular}{|lll|}
\hline $\begin{array}{l}\text { Age group } \\
\text { (yrs) }\end{array}$ & No. of patient & Percentage \\
\hline $31-35$ & 2 & $4 \%$ \\
\hline $36-40$ & 14 & $28 \%$ \\
\hline $41-45$ & 21 & $42 \%$ \\
\hline $46-50$ & 12 & $24 \%$ \\
\hline $51-55$ & 1 & $2 \%$ \\
\hline
\end{tabular}

In our study, maximum age incidence was between 41-45 years- $42 \%$, followed by $36-40$ years - $28 \%$. Among 50 patients, 45 cases $(90 \%)$ were multipara and 5 cases (10\%) were primipara. Among 45 cases of multipara, 5 cases were grand multipara. Among 50 patients, $50 \%$ had normal BMI (18.5-24.99), 28\% were overweight (2529.99), $14 \%$ were obese $(>30)$ and $4 \%$ were underweight $(<18.5)$. Associated medical conditions were seen as follows in our study; $18 \%$ were hypertensive, $14 \%$ were anemic, $6 \%$ were diabetic, $2 \%$ were cardiac patients and $60 \%$ were non anaemic. 
Table 2: Complaints.

\begin{tabular}{|ll|l|}
\hline Complaints & $\begin{array}{l}\text { No of the } \\
\text { patients }\end{array}$ & Percentage \\
\hline HMB (Menorrhagia) & 26 & $52 \%$ \\
\hline $\begin{array}{l}\text { Frequent and HMB } \\
\text { (Polymenorrhagia) }\end{array}$ & 9 & $18 \%$ \\
\hline $\begin{array}{l}\text { Irregular and HMB } \\
\text { (Menometrorrhagia) }\end{array}$ & 4 & $8 \%$ \\
\hline $\begin{array}{l}\text { Infrequent cycles } \\
\text { (Oligomenorrhea) }\end{array}$ & 2 & $4 \%$ \\
\hline $\begin{array}{l}\text { Frequent cycles } \\
\text { (Polymenorrhea) }\end{array}$ & 3 & $6 \%$ \\
\hline $\begin{array}{l}\text { HPMB (Heavy and } \\
\text { prolonged menstrual } \\
\text { bleeding) }\end{array}$ & 4 & $8 \%$ \\
\hline IMB (Metrorrhagia) & 2 & $4 \%$ \\
\hline
\end{tabular}

In the present study, $54 \%$ of cases presented with Heavy Menstrual Bleeding (HMB), $18 \%$ presented with Frequent and Heavy Menstrual Bleeding, 8\% each with Irregular and Heavy Menstrual Bleeding and Heavy and Prolonged Menstrual Bleeding. Frequent cycles correspond to $6 \%$, Infrequent cycles and Inter-Menstrual Bleeding corresponds to $4 \%$ each (Table 2).

Table 3: Age distribution and complaints.

\begin{tabular}{|lllllll|}
\hline Conditions & \multicolumn{7}{l}{ Age of the patients (in years) } \\
& $\begin{array}{l}\mathbf{3 1 -} \\
\mathbf{3 5}\end{array}$ & $\begin{array}{l}\mathbf{3 6}- \\
\mathbf{4 0}\end{array}$ & $\begin{array}{l}\mathbf{4 1}- \\
\mathbf{4 5}\end{array}$ & $\begin{array}{l}\mathbf{5 0} \\
\mathbf{5 0}\end{array}$ & $\begin{array}{l}\mathbf{5 1 -} \\
\mathbf{5 5}\end{array}$ & Total \\
\hline $\begin{array}{l}\text { Frequent } \\
\text { and HMB }\end{array}$ & 0 & 8 & 10 & 7 & 1 & 26 \\
\hline $\begin{array}{l}\text { Irregular } \\
\text { and HMB }\end{array}$ & 1 & 1 & 0 & 2 & 0 & 4 \\
\hline $\begin{array}{l}\text { Infrequent } \\
\text { cycles }\end{array}$ & 0 & 1 & 1 & 0 & 0 & 2 \\
\hline HPMB & 0 & 2 & 2 & 0 & 0 & 4 \\
\hline $\begin{array}{l}\text { Frequent } \\
\text { cycles }\end{array}$ & 0 & 0 & 2 & 1 & 0 & 3 \\
\hline IMB & 1 & 0 & 0 & 1 & 0 & 2 \\
\hline Total & 2 & 15 & 20 & 12 & 1 & 50 \\
\hline
\end{tabular}

$50 \%$ patients had abnormal uterine bleeding for 6 months to 1 year duration. $24 \%$ patients had $12-18$ months, $22 \%$ had 3-6months and 4\% had 18-24 months. The presentation of $28 \%$ of women who sought medical help after 1 year of symptoms shows lack of awareness in low socio-economic class and social hindrance (Table 3). Ultrasonography revealed bulky uterus in $66 \%$ of cases and normal uterus in $34 \%$ of cases. In the present study, $72 \%$ of patients had endometrial thickness of about 4$10 \mathrm{~mm}$ and $28 \%$ had more than $10 \mathrm{~mm}$ in ultrasonography.

Table 4 shows hysteroscopic findings. Abnormal findings were seen in $74 \%$ of cases, while in the remaining $26 \%$ of cases, no abnormality was detected (negative hysteroscopic view). Endometrial Hyperplasia (42\%) was the most common abnormal finding, followed by polypoidal endometrium with mucosal Polyps (22\%).
There were also $4 \%$ of Submucous Myomas, $2 \%$ of carcinoma and $2 \%$ each of synechiae and endometritis.

Table 4: Hysteroscopic findings.

\begin{tabular}{|lll|}
\hline $\begin{array}{l}\text { Hysteroscopic } \\
\text { findings }\end{array}$ & $\begin{array}{l}\text { No of the } \\
\text { patients }\end{array}$ & Percentage \\
\hline $\begin{array}{l}\text { Proliferative type } \\
\text { Secretory type }\end{array}$ & 9 & $18 \%$ \\
\hline $\begin{array}{l}\text { Hyperplastic } \\
\text { endometrium }\end{array}$ & 21 & $8 \%$ \\
\hline $\begin{array}{l}\text { Polypoidal } \\
\text { endometrium }\end{array}$ & 7 & $42 \%$ \\
\hline Mucosal polyp & 4 & $14 \%$ \\
\hline $\begin{array}{l}\text { Submucosal } \\
\text { myoma }\end{array}$ & 2 & $8 \%$ \\
\hline $\begin{array}{l}\text { Carcinoma } \\
\text { Intrauterine } \\
\text { synechiae }\end{array}$ & 1 & $4 \%$ \\
\hline Endometritis & 1 & $2 \%$ \\
\hline
\end{tabular}

In ours study, histopathological report showed abnormal findings in 35 patients $(70 \%)$, while in the remaining 15 patients $(30 \%)$, it showed proliferative phase $(18 \%)$ and secretory phase endometrium (12\%). In Histopathological examination, Endometrial Hyperplasia was the most common finding (38\%). In that, simple cystic hyperplasia with atypia was $6 \%$ and without atypia was $26 \%$, followed by complex cystic hyperplasia with atypia was $2 \%$ and without atypia was $4 \%$. Other histopathological reports were: endometrial polyps in $14 \%$, irregular shedding in $10 \%$, well differentiated adenocarcinoma in $4 \%$, chronic endometritis in $2 \%$ and atrophic endometrium in $2 \%$ (Figure 1).

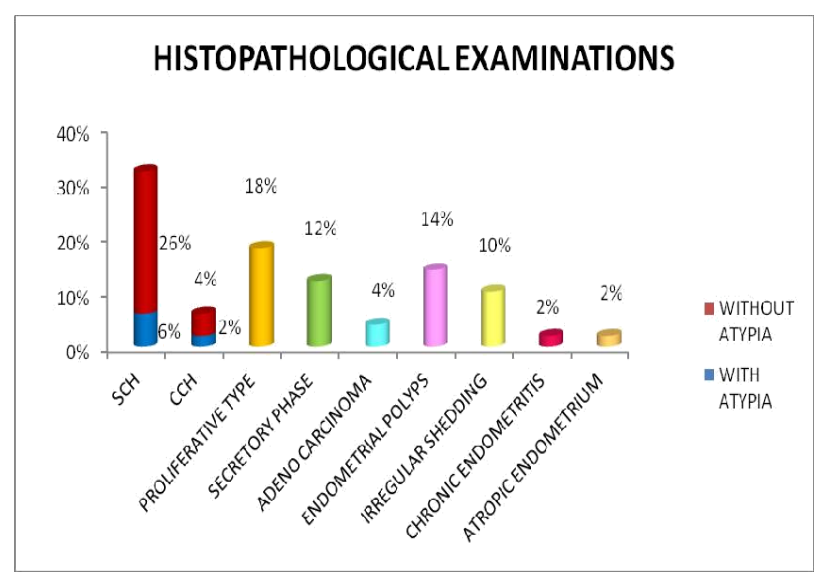

Figure 1: Histopathological examinations.

In this study, we observed smooth to slightly rough surface in proliferative and secretory phase. Pink surface in hyperplastic endometrium. An according to this study, the accuracy of hysteroscopy in diagnosing mucosal polyps, submucosal myomas, endometritis and synechiae are $100 \%$. But diagnosis of endometrial hyperplasia has to be confirmed with histopathological examinations. 
Table 5: Surface of endometrium.

\begin{tabular}{lll} 
Surface & No. of patients & Percentage \\
\hline Smooth & 10 & $20 \%$ \\
\hline Pink & 14 & $28 \%$ \\
\hline Rough & 13 & $26 \%$ \\
\hline Pale & 3 & $6 \%$ \\
\hline Polyp & 7 & $14 \%$ \\
\hline Myoma & 2 & $4 \%$ \\
\hline Irregular and necrotic & 1 & $2 \%$ \\
\hline
\end{tabular}

Table 6: Glandular pores.

\begin{tabular}{lll} 
Glandular pores & No of patients & Percentage \\
\hline Regular & 6 & $12 \%$ \\
\hline Not well delineated & 16 & $32 \%$ \\
\hline Not seen & 13 & $26 \%$ \\
\hline Seen & 12 & $24 \%$ \\
\hline Shiny discrete & 3 & $6 \%$ \\
\hline
\end{tabular}

In our study, the glandular pores were not well delineated in hyperplasia and not seen in irregular shedding cases (Table 6).

In our study, Hyperplastic, polypoidal and Irregular shedding endometrium are highly vascular and congestive. Secretory phase endometrium showed typical geometric pattern.

Table 7: Vascularisation.

\begin{tabular}{|lll|}
\hline Vascularivation & No of the patient & Percentage \\
\hline Less vascular & 4 & $8 \%$ \\
\hline Highly vascular & 20 & $40 \%$ \\
\hline Congestive & 8 & $16 \%$ \\
\hline Rich net pattern & 2 & $4 \%$ \\
\hline Poorly seen & 6 & $12 \%$ \\
\hline Not seen & 1 & $2 \%$ \\
\hline Geometric pattern & 4 & $8 \%$ \\
\hline Polyp & 3 & $6 \%$ \\
\hline
\end{tabular}

Table 8: Validity of hysteroscopy.

\begin{tabular}{|llll|}
$\begin{array}{l}\text { Hysteroscopic } \\
\text { finding }\end{array}$ & $\begin{array}{l}\text { Disease } \\
\text { present }\end{array}$ & $\begin{array}{l}\text { Actually } \\
\text { alosent }\end{array}$ & Total \\
\hline Positive & $34(\mathrm{a})$ & 1 (b) & $\mathrm{a}+\mathrm{b}=35$ \\
\hline Negative & $3(\mathrm{c})$ & $12(\mathrm{~d})$ & $\mathrm{c}+\mathrm{d}=15$ \\
\hline Total & $\mathrm{a}+\mathrm{c}=37$ & $\mathrm{~b}+\mathrm{d}=13$ & $\begin{array}{l}\mathrm{a}+\mathrm{b}+\mathrm{c}+\mathrm{d}= \\
50\end{array}$ \\
\hline
\end{tabular}

- $\quad$ Sensitivity: a $/ a+c \times 100=91.89 \%$

- $\quad$ Specificity: d / b+d x $100=92.31 \%$

- Positive Predictive Value: a / a+b x $100=97.14 \%$

- Negative Predictive Value: d / c+d x $100=80 \%$

- False Positive Rate: b / b+d x $100=7.69 \%$

- False Negative rate: $c / a+c$ x $100=8.1 \%$

- Concordance (Accuracy): $a+d / a+b+c+d \times 100=92$ $\%$

- $\quad 3 / 4$ Kappa statistics - 0.80, Good Agreement
Validity of hysteroscopy for Proliferative endometrium was as follows: Sensitivity-77.78\%, specificity-95.12\%, positive predictive value-77.78\%, negative predictive value-95.12\%, accuracy-92\%, Kappa statistics-0.73 (good agreement). Validity of hysteroscopy for Secretory endometrium was as follows: Sensitivity-66.67\%, specificity-100\%, positive predictive value-100\%, negative predictive value-95.65\%, accuracy-96\%, Kappa statistics-0.80 (good agreement). Validity of hysteroscopy for endometrial hyperplasia was as follows: Sensitivity-78.95\%, specificity-80.65\%, positive predictive value- $71.43 \%$, negative predictive value$86.21 \%$, accuracy- $80 \%$, Kappa statistics-0.58 (moderate agreement). Validity of hysteroscopy for submucosal myoma was as follows: Sensitivity-100\%, specificity$100 \%$, positive predictive value-100\%, negative predictive value-100\%, accuracy-100\%, Kappa statistics1 (very good agreement). Validity of hysteroscopy for polypoidal endometrium was as follows: Sensitivity$100 \%$, specificity-92.86\%, positive predictive value$72.73 \%$, negative predictive value-100\%, accuracy-94\%, Kappa statistics-0.80 (good agreement).

Validity of hysteroscopy for carcinoma endometrium was as follows: Sensitivity-50\%, specificity-100\%, positive predictive value-100\%, negative predictive value$97.96 \%$, accuracy-98\%, Kappa statistics-0.65 (good agreement). Compared with Histopathological examination, hysteroscopy missed 2 findings of Simple Cystic Hyperplasia without atypia. 5 cases of irregular shedding in histopathological report have been interpreted as hyperplastic (4 cases) and polypoidal endometrium (1 case) in Hysteroscopy.

Similarly, 2 cases of myomas and 1 case of synechiae have been interpreted as proliferative / secretory phase and atrophic endometrium in histopathological examination respectively. In 1 patient, hysteroscopic finding of hyperplasia has been interpreted as secretory phase in histolpathogical examination.

Table 9: final diagnosis after hysteroscopy.

\begin{tabular}{|c|c|c|c|c|c|c|c|c|}
\hline$\frac{\sqrt[n]{E}}{\sqrt{\frac{0}{E}}}$ & $\sum^{\infty}$ & 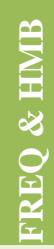 & 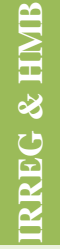 & $\begin{array}{l}\frac{y}{3} \\
\frac{8}{3} \\
\frac{8}{2} \\
\frac{0}{2} \\
\frac{0}{2}\end{array}$ & $\sum_{\text {E. }}^{\oplus}$ & 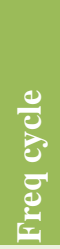 & $\sum$ & E़ \\
\hline Normal & 7 & 3 & 1 & 1 & 1 & 0 & 0 & 13 \\
\hline Hyperplasia & 11 & 6 & 3 & 0 & 1 & 0 & 0 & 21 \\
\hline Polyp & 4 & 0 & 0 & 0 & 2 & 3 & 2 & 11 \\
\hline Myoma & 2 & 0 & 0 & 0 & 0 & 0 & 0 & 2 \\
\hline Carcinoma & 1 & 0 & 0 & 0 & 0 & 0 & 0 & 1 \\
\hline Synechiae & 0 & 0 & 0 & 1 & 0 & 0 & 0 & 1 \\
\hline Endometritis & 1 & 0 & 0 & 0 & 0 & 0 & 0 & 1 \\
\hline Total & 26 & 9 & 4 & 2 & 4 & 3 & 2 & 50 \\
\hline
\end{tabular}


Table 10: Final Diagnosis after histopathological examination.

\begin{tabular}{|c|c|c|c|c|c|c|c|c|}
\hline Complaints & $\sum^{\infty}$ & 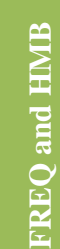 & 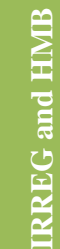 & $\begin{array}{l}\frac{y}{0} \\
\frac{d}{0} \\
8 \\
8 \\
\frac{\pi}{2} \\
\frac{\pi}{2}\end{array}$ & $\sum_{i=}^{\infty}$ & 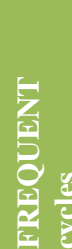 & $\sum_{i}^{e}$ & 롤 \\
\hline Normal & 8 & 3 & 2 & 1 & 0 & 1 & 0 & 15 \\
\hline Hyperplasia & 9 & 5 & 1 & 0 & 2 & 2 & 0 & 19 \\
\hline Polyp & 3 & 0 & 0 & 0 & 2 & 0 & 2 & 7 \\
\hline $\begin{array}{l}\text { Irregular } \\
\text { shedding }\end{array}$ & 3 & 1 & 1 & 0 & 0 & 0 & 0 & 5 \\
\hline Carcinoma & 2 & 0 & 0 & 0 & 0 & 0 & 0 & 2 \\
\hline Atrophic & 0 & 0 & 0 & 1 & 0 & 0 & 0 & 1 \\
\hline Endometritis & 1 & 0 & 0 & 0 & 0 & 0 & 0 & 1 \\
\hline Total & 26 & 9 & 4 & 2 & 4 & 3 & 2 & 50 \\
\hline
\end{tabular}

Hysteroscopy has missed 1 case of carcinoma endometrium which has been interpretated as Hyperplastic endometrium. No postoperative complications in this study.

\section{DISCUSSION}

In the present study, diagnostic hysteroscopy was done in 50 premenopausal women with AUB and its correlation with histopathological findings was sought. Among the premenopausal women, the maximum incidence of AUB in this study was found to be 41-45 years. Panda11 found that maximum age incidence was between $35-45 \mathrm{yrs}$ in range between 25-70yrs. Patil SG10 found the maximum age prevalence was 26-30 years and 41-45 years (22\%). Guin gita12 found the maximum age incidence was between $36-40$ years (22\%) followed by $41-45$ years (20\%). The commonest presenting complaint in our study was heavy menstrual bleeding (menorrhagia) in 54\% of the cases followed by frequent and heavy menstrual bleeding (polymenorrhagia) in $18 \%$ of the cases. In Guin gita's 12 study, $30 \%$ cases had menorrhagia followed by $16 \%$ had Menometrorrhagia and oligomenorrhea each. Out of 9 cases of proliferative endometrium on histopathology, 7 cases were identified on hysteroscopy. One case was interpreted as submucosal myoma and 1 case as polypoidal endometrium on hysteroscopy. Out of 6 cases of secretory endometrium on histopathology, 4 were diagnosed on hysteroscopy. Among the other two cases, 1 case was submucosal myoma and 1 case was described as hyperplastic endometrium on hysteroscopy. Nineteen cases of hyperplasia were diagnosed on histopathology, but 21 cases were suspected of hyperplasia on hysteroscopy. Among the 19 cases, 2 cases are interpreted as proliferative endometrium and 1 as polypoidal endometrium by hysteroscopy. Out of 21 cases of hyperplasia on hysteroscopy, 1 showed carcinoma endometrium, 9 showed simple hyperplasia without atypia, 3 showed simple hyperplasia with atypia,
2 showed complex hyperplasia without atypia and 1 case showed complex hyperplasia with atypia, 1 case showed secretory endometrium, and 4 cases showed irregular shedding on histopathologic examination. Out of 19 cases of hyperplasia on histopathology, 13 cases were of simple hyperplasia without atypia, 3 cases were of simple hyperplasia with atypia, 2 cases were of complex hyperplasia without atypia and 1 case was of complex hyperplasia with atypia.

In this study, one case suspected as carcinoma endometrium was diagnosed on hysteroscopy by hyperplasia with areas of necrosis, increased vascularity and hemorrhage. Later it was confirmed on histopathology as well differentiated adenocarcinoma. One more case of carcinoma endometrium has been interpretated as hyperplasia on hysteroscopy. Hysteroscopy showed submucous myomas in 2 cases which has been interpretated as proliferative and secretory type of endometrium in histopathological examination. On hysteroscopy, 1 case was found to be intrauterine synechiae but histopathological report showed as atrophic endometrium. Hysteroscopy showed mucosal polyps in 4 cases and all were confirmed on histopathological examination. Polypoidal endometrium had been suspected in 7 cases on hysteroscopy, 4 cases were confirmed on histopathological examination. 1 case was reported as late proliferative phase, 1 as simple cystic hyperplasia without atypia and 1 as irregular shedding. Our results are comparable to studies shown in Table 11

Accuracy of hysteroscopic findings were $92 \%$, misinterpretation was $8 \%$ in our study. F test value $=309.7$. This is comparable to study conducted by Panda11 (92.69\% and $7.31 \%$ respectively).

Table 11: Normal and abnormal findings at hysteroscopy.

\begin{tabular}{|c|c|c|c|}
\hline Authors (yrs) & $\begin{array}{l}\text { Sample } \\
\text { size }\end{array}$ & Normal & Abnormal \\
\hline Hong-Lan Zhu ${ }^{13}$ & 90 & $2(2.2 \%)$ & $88(97.8 \%)$ \\
\hline Patil SG ${ }^{10}$ & 100 & $50 \%$ & $50 \%$ \\
\hline Van Dongen $\mathrm{H}^{8}$ & $\begin{array}{l}\text { Meta- } \\
\text { analysis }\end{array}$ & $3.1 \%$ & $96.9 \%$ \\
\hline Guin $\mathrm{G}^{12}$ & 100 & $26 \%$ & $74 \%$ \\
\hline Stefanescu $\mathrm{A}^{14}$ & 1545 & $21 \%$ & $79 \%$ \\
\hline Sheth ${ }^{15}$ & 51 & $44 \%$ & $56 \%$ \\
\hline Panda $^{11}$ & 66 & $46.6 \%$ & $53.4 \%$ \\
\hline Gianninoto $^{16}$ & 512 & $25 \%$ & $75 \%$ \\
\hline $\begin{array}{l}\text { Trajkovic } \\
\text { Dinic }^{17}\end{array}$ & 239 & $41 \%$ & $59 \%$ \\
\hline Present series & 50 & $26 \%$ & $74 \%$ \\
\hline
\end{tabular}

Sensitivity and specificity of hysteroscopy in our study is $91.89 \%, 92.31 \%$ respectively which is comparable to other studies like Loverra et al (98\% and 95\%), HongLan Zhu (77.8\% and 100\%). ${ }^{13,19}$ In other studies, like De wit Ac et al sensitivity is $63 \%$ and specificity is $55 \%$, Fernandez-perra found it to be $36 \%$ and $98 \%$ 
respectively. ${ }^{18,20}$ Uno $\mathrm{LH}$ et al found it to be $15.79 \%$ and $97.29 \%$ respectively. ${ }^{21}$

Diagnostic accuracy, sensitivity, specificity, positive and negative predictive of hysteroscopy in the present study.

\section{Group I: patients with proliferative endometrium}

In the present study, diagnostic accuracy of hysteroscopy for proliferative endometrium was 92\%. Sensitivity, specificity, positive predictive value and negative predictive value of hysteroscopy for proliferative endometrium compared to histopathology were $77.78 \%$, $95.12 \%, 77.78 \%$ and $95.12 \%$, respectively.

\section{Group II: patients with secretory endometrium}

In the present study, diagnostic accuracy of hysteroscopy for secretory endometrium was $96 \%$. So, sensitivity, specificity, positive predictive value and negative predictive value of hysteroscopy for secretory endometrium were $66.67 \%, 100 \%, 100 \%$ and $95.65 \%$, respectively.

\section{Group III: patients with hyperplastic endometrium}

In the present study, diagnostic accuracy of hysteroscopy for hyperplastic endometrium was $80 \%$. So, sensitivity, specificity, positive predictive value and negative predictive value of hysteroscopy for hyperplastic endometrium were $78.95 \%, 80.65 \%, 71.43 \%$ and $86.21 \%$, respectively. It was comparable to other studies like Patil SG $10(75 \%, 92.5 \%, 71.4 \%, 93.67 \%$ respectively), Birinyi L 22 (52\%, 92\%, 35\%, 95\% respectively).

\section{Group IV: patients with Submucous myoma}

Diagnostic accuracy of hysteroscopy for submucous myomas was $100 \%$ in this present study.

\section{Group V: patients with polypoidal endometrium}

In this present study, diagnostic accuracy of hysteroscopy for polypoidal endometrium was $94 \%$. So, sensitivity, specificity, positive predictive value and negative predictive value of hysteroscopy for polypoidal endometrium were $100 \%, 92.86 \%, 72.73 \%$ and $100 \%$, respectively. Our study results are comparable to other studies $(100 \%, 95.78 \%, 55.55 \%, 100 \%$ respectively) and Birinyi L 22 (87\%, 89\%, 66\%, 96\% respectively).

\section{Group VI: patients with Carcinoma endometrium}

In this present study, diagnostic accuracy of hysteroscopy for carcinoma endometrium was $98 \%$. So, sensitivity, specificity, positive predictive value and negative predictive value of hysteroscopy for carcinoma endometrium were $50 \%, 100 \%, 100 \%$ and $97.96 \%$ respectively. Our study results were comparable to other studies like Patil SG 10 (100\%, 98.97\%, 66.66\%, 100\%) and Birinyi L 22 (68\%, 9\%, 68\%, 99\% respectively).

\section{CONCLUSION}

Diagnostic hysteroscopy is currently a widely accepted, simple, feasible and highly sensitive diagnostic tool for the visualization of endometrial cavity with excellent image quality and magnification in patients with abnormal uterine bleeding. It is a valuable and minimally invasive technique which helps in identifying areas with most suspicious appearance where targeted biopsy can be taken. This is a far more accurate form of diagnosing any intrauterine pathology than blind $\mathrm{D}$ and $\mathrm{C}$ which often may miss small lesions, location and volume of endometrial disease in most cases. Adequate diagnosis is mandatory for selection of appropriate treatment of any women with abnormal uterine bleeding.

Since Hysteroscopy is certainly the most accurate, cost effective diagnostic and treatment modality of choice for many intrauterine conditions, it should be the essential skill of all Gynaecologists.

This study highlights "Hysteroscopy and its directed biopsy with Histopathological examination" will be the "new gold standard technique" for evaluation of abnormal uterine Bleeding.

\section{ACKNOWLEDGEMENTS}

Authors are all thankful for their OT staff, our patients, colleagues, postgraduate students for their contribution to the work. Special thanks to our Head of the department Dr Renuka ramaiah, our MS Dr. Rachita Biswas and Our Dean Dr. Rajeev Shetty. We are also thankful to the Almighty GOD for his blessings.

Funding: No funding sources Conflict of interest: None declared

Ethical approval: The study was approved by the Institutional Ethics Committee

\section{REFERENCES}

1. Lasmar RB, Dias R, Barrozo PRM, Oliveira MAP, Coutinho EDSF, da Rosa DB. Prevalence of hysteroscopic findings and histologic diagnoses in patients with abnormal uterine bleeding. Fertil Steril. 2008;89:1803-7.

2. Schorge JO, Schaffer JI, Halvorson LM, Hoffman BL, Bradshaw KD, Cunningham FG, (eds). Publisher Mc Graw Hill; 2008:950-53.

3. Sweet MG, Schmidt-Dalton TA, Weiss PM MK. Evaluation and Management of Abnormal Uterine Bleeding in Premenopausal Women. Am Fam Physician. 2012;85:35-43.

4. Kotdawala P, Kotdawala S, Nagar N. Evaluation of endometrium in peri-menopausal abnormal uterine bleeding. J Midlife Health. 2013;4:16-21. 
5. Stock RJ, Kanbour A. Prehysterectomy curettage. Obstet. 1975;45:537-41.

6. John A Rock, Howard W. Jones III (eds). New Delhi: Wolters Kluwer health and Lippincott Williams \& Wilkins. 2009;336-68.

7. Pasqualotto EB, Margossian H, Price LL. Accuracy of preoperative diagnostic tools and outcomes of hysteroscopic management of menstrual dysfunction. J Am Assoc Gynecol Laparosc. 2000;7:201-9.

8. Van Dongen H, de Kroon CD, Jacobi CE, Trimbos JB, Jansen FW. Diagnostic hysteroscopy in abnormal uterine bleeding: a systematic review and metaanalysis. BJOG. 2007;114:664-75.

9. Valle RE. Hysteroscopic evaluation of patients with abnormal uterine Bleeding. Surg Gynecol Obstet 1981;153:521-23.

10. Patil SG, Bhute SB, Inamdar SA, Acharya NS, Shrivastava DS. Role of Diagnostic Hysteroscopy in Abnormal Uterine Bleeding and its Histopathologic Correlation. J Gynecol Endosc Surg. 2009;1:98-104.

11. Panda A, Parulekar SV, Gupta A. Diagnostic hysteroscopy in abnormal uterine bleeding and histopathological correlation. J Obstet Gynaecol India. 1999;49:74-6.

12. Guin G, Sandhu SK, Lele A, Khare S. Hysteroscopy in evaluation of abnormal uterine bleeding. J Obstet Gynaecol India. 2011;61:546-9.

13. Hong-lan ZHU, Xu-dong L, Jian-liu W, Heng CUI, Li-hui WEI. Hysteroscopy and directed biopsy in the diagnosis of endometrial carcinoma. Chin Med J. 2010;123:3524-8.

14. Stefanescu A, Marinescu B. Diagnostic Hysteroscopy - A Retrospective Study of 1545 Cases. maedica a J Clin Med. 2012;7:309-14.
15. Sheth S, Hamper VM, Kurman R. A study between hysteroscopy with directed biopsies and dialatation and curettage. Am J Obstet Gynecol. 1989;158:489.

16. Gianninoto A, Morana C, Campione C. Diagnostic hysteroscopy in abnormal uterine bleeding. Five years' experience. Minerva Ginecol. 200355:57-61.

17. Trajkovic Dinic SP. Role of Hysteroscopy in Evaluation of Patients with Abnormal Uterine Bleeding. Acta Facultatis Medicae Naissensis. 2011;28:177-81.

18. De Wit AC, Vleugels MP, de Kruif JH. Diagnostic hysteroscopy: a valuable diagnostic tool in the diagnosis of structural intra-cavital pathology and endometrial hyperplasia or carcinoma? Eur J Obstet Gynecol Reprod Biol. 2003;110:79-82.

19. Loverro G, Bettocchi S, Cormio G, Nicolardi V, Porreca MR, Pansini N et al. Diagnostic accuracy of hysteroscopy in endometrial hyperplasia, Maturitas. 1996;25:187-91.

20. Fernández-Parra J, Rodríguez Oliver A, López Criado S, Parrilla Fernández F, Montoya Ventoso F. Hysteroscopic evaluation of endometrial polyps. Int J Gynaecol Obstet. 2006;95:144-8.

21. Uno LH, Carvalho FM, Bagnoli VR, Fonsecaa AM, Pinotti JA. Morphologic hysteroscopic criteria suggestive of endometrial hyperplasia. Int $\mathbf{J}$ Gynaecol Obstet. 1995;49:35-40.

22. Birinyi L, Darago' P, Torok P, Csisza'r P, Major T, Borsos a, et al. Predictive value of hysteroscopic examination in intrauterine abnormalities. Eur J Obstet Gynecol Reprod Biol. 2004;115:75-9.

Cite this article as: Kumar AK, Sathya P, Sampathkumar S. Study of hysteroscopic evaluation in patients with abnormal uterine bleeding. Int J Reprod Contracept Obstet Gynecol 2017;6:1413-9. 